\title{
Original Article \\ CLINICAL RISK INDEX FOR BABIES (CRIB SCORE) AS A PREDICTOR OF NEONATAL MORTALITY
}

\author{
Zarmast Khan ${ }^{\mathrm{a}}$, Nasir Zulfiqar ${ }^{\mathrm{b}}$, Hamid Mahmood ${ }^{\mathrm{c}}$, Amara Waqar ${ }^{\mathrm{d}}$, Awais Gohar ${ }^{\mathrm{e}}$ \\ ${ }^{a}$ Assistant Professor, Pediatrics, Shifa International Hospital, Islamabad. \\ ${ }^{b}$ Associate Professor, Surgery, Sir Syed Institute of Medical Sciences, Karachi. \\ 'Professor, Biochemistry, Shaheed Zulfiqar Ali Bhutto Medical University, Islamabad. \\ dDirector Quality Enhancement Cell, Gulab Devi Hospital, Lahore. \\ 'University of Lahore, Lahore.
}

\begin{abstract}
:
OBJECTIVE: It is very important to predict the outcome among preterm and very low birth weight babies as mortality rates are quite high. CRIB score is used to predict the outcomes in preterm neonates. The objective of this study was to determine the strength of CRIB score in detecting neonatal mortality in babies presenting with very low birth weight.

STUDY DESIGN: Cross-sectional study.

SUBJECTS: A total of 254 newborns with birth weight of between 500 to 1500 grams and gestational age of $\leq 35$ weeks were included. The study was conducted over a period of 6 months in neonatology department of Shifa International Hospital, Islamabad.

METHODS: CRIB score was obtained through a prospective way in all neonates and its association was assessed with mortality during neonatal intensive care unit (NICU) stay.

RESULTS: The percentage of male and female newborn subjects was $54.3 \%(n=138)$ and $45.7 \%$ $(n=116)$ respectively. Mean gestational age was 33.3 weeks \pm 1.04 and mean birth weight of study population was 1129.9 grams \pm 210.6 . Mean CRIB score among the study population was $6.3 \pm 3.1$ and overall mortality was found to be $54.7 \%(n=139)$. Mean CRIB score was found to be $8.27 \pm 2.1$ among mortality group and it was $3.87 \pm 3.4$ among newborns who were discharged $(P<0.05)$. Mortality was present in $4.3 \%(n=4)$ of neonates with CRIB score between $1-5,87.1 \%(n=121)$ who had CRIB score between $6-10$ and $100 \%(n=14)$ of neonates who had CRIB score between 11$15(P<0.05)$.

CONCLUSION: Significantly higher mortality was noted among neonates with higher CRIB scores. KEYWORDS: CRIB score, Neonatal mortality, Premature birth.
\end{abstract}

\section{INTRODUCTION:}

Preterm deliveries and babies with very low birth weight (VLBW) are at risk of developing severe morbidity and mortality ${ }^{[1,2]}$. Very low birth weight infants are in a need of advance medical care, as common interventions and treatments cannot save their $\operatorname{life}^{[3]}$. There are more than 6.2 million prenatal deaths around the world each year. Most of them occurs between a period of 7-28 days of their early life. More than $74 \%$ of the prenatal deaths occurs due to very low birth weight of the infants. The other major causes are birth asphyxia and infections in the hospital. This high morbidity and mortality rate has raised questions for the health. Professionals who are actively involved with neonatal care in $\mathrm{ICU}^{[4]}$. A need was felt by the health care providers to develop a clinical risk index for babies (CRIB) to find out quality of life pattern of infants and other risk assessments in order to detect high mortality rate in the neonatal deaths ${ }^{[5]}$.

The CRIB score was published by the international neonatal network in year 1993. It formed the basis to collect data from the parents within 12 hours after the birth of their

Corresponding Author:
Zarmast Khan
Issistant Professor,
Islamabadrics, Shifa International Hospital,


neonates. Initially CRIB score has included 6 variables which were differentiated in to four levels ${ }^{[6]}$. With the advancement in prenatal medication and sophistication of the instruments for the neonatal intensive care units, the rate of neonatal morbidity and mortality rates have become low. The objective of this study is to find out different variables which are related to high morbidity in very low birth weight infants ${ }^{[7]}$. More commonly used variables to identify the risk factors, which may aggravate the high rate of mortality are considered to be gestational age and birth weight $^{[8,9]}$.

It has been estimated that 131 million babies are born and more than 15 million die before their $10^{\text {th }}$ birthday. There is approximation of 8.1 million babies who cannot complete their first year of life. Different countries have set their development goals as per world summit for children, United Nations Millennium Declaration $^{[10]}$ and United Nations special session on children ${ }^{[11]}$, the preterm birth rate is variable throughout the world from Africa to Europe, which is 5\% in Europe and $18.2 \%$ in Africa $^{[12]}$ of these preterm births, $84 \%$ usually occurs between 31 to 36 weeks of gestational age. The mortality rate is very high in lowincome countries as compared to high income countries where preterm birth rate is low $^{[13]}$.

Keeping in mind the high mortality rates after preterm birth and very low birth weight, it is very important to assess these babies with special attention and top most care. If the outcome is predicted within first few hours after birth, the clinicians may intervene timely and with proper management, serious morbidity and mortality rates may be reduced. We planned to determine the strength of CRIB score in predicting neonatal mortality.

\section{OBJECTIVES:}

To determine the strength of CRIB score in detecting neonatal mortality in babies presenting with very low birth weight.

\section{MATERIALS AND METHODS:}

\section{SETTING:}

Department of Neonatology, Shifa International Hospital, Islamabad.

\section{DURATION:}

Six months.

\section{SAMPLE SIZE:}

The sample size was calculated by using WHO calculator with the statistical assumptions of $95 \%$ power and $5 \%$ alpha error, prediction of mortality $21.0 \%$ from previous literature. The sample size came out to be 254 neonates.

\section{SAMPLING TECHNIQUE:}

Non-probability consecutive sampling technique.

\section{STUDY DESIGN:}

Cross sectional study.

\section{SAMPLE SELECTION:}

\section{INCLUSION CRITERIA:}

1. Neonates with gestational age $\leq 35$ weeks.

2. Weight at birth between 500-1500 grams.

3. Neonates born on the same day and shifted to Shifa International Hospital, Islamabad.

4. Newborns delivered in Shifa international hospital, Islamabad.

\section{DATA COLLECTION PROCEDURE:}

Study was conducted in nursery and neonatal intensive care unit of Shifa International Hospital, Islamabad having more than 1500 admission per month including inborn and babies delivered in Shifa International Hospital, Islamabad. All neonates delivered here in nursery were given serial numbers and CRIB score was calculated by a trained neonatologist and all babies were followed till their presence in hospital to know outcome. Arterial blood gas (ABG's) analysis was done with 12 hour interval. Informed consent was taken from the parents or caretakers. Two hundred and fifty four patients fulfilling inclusion criteria were registered.

The details regarding birth weight $(\mathrm{kg})$, gestational age started from last menstrual period (ballard score and from early scans) and 
congenital malformations, all were recorded in a pretested structured proforma The assessments was made according to the 6 clinical parameters of CRIB score. The total score was entered in the proforma. Patients were followed on daily basis until the final outcome i.e. complete or partial recovery or death. All the information was collected by the research himself to limit the selection bias and human errors.

\section{DATA ANALYSIS PROCEDURE:}

All the collected data was entered into SPSS version 16 and analyzed. The qualitative data like gender, mortality and CRIB score levels were analyzed as frequency and percentages.

The quantitative data like age, gestational age and CRIB score were analyzed as means and standard deviations. Independent sample t-test was applied to see the significance of difference between mean CRIB score among mortality and discharge group. Chi-square test was applied to see the significance of difference in percentage mortality among different CRIB score levels. P-
Value of $<0.05$ was considered as significant. Data was depicted in tables and graphs.

\section{RESULTS:}

\section{DEMOGRAPHY OF THE SELECTED POPULATION:}

CRIB score was obtained through a prospective way from a total of two hundred and fifty four $(n=254)$ newborns with birth weight of 500 to $1500 \mathrm{~g}$ and gestational age $\leq 35$ weeks. Out of total two hundred and fifty four $(n=254)$ newborns, $54.3 \%(n=138)$ were males with mean gestational age of 33.3 weeks \pm 1.03 and $45.7 \% \quad(n=116)$ were females with mean gestational age of 33.4 weeks \pm 1.05 . Total mean gestational age was 33.3 weeks \pm 1.04 . Mean birth weight among males was 1107.8 grams \pm 223.4 and mean birth weight among females was 1156.1 grams \pm 192.1 . Total mean birth weight of study population was 1129.9 grams \pm 210.6 (table I).

Table-I: Demographic Characteristics of Study Population.

\begin{tabular}{|c|c|c|c|}
\hline & $\overline{\mathbf{G E}}$ & DER & Total \\
\hline & Male & Female & \\
\hline Frequency (\%) & $138(54.3)$ & $116(45.7)$ & $254(100.0)$ \\
\hline Mean \pm Std (gestational age) & $33.3 \pm 1.03$ & $33.4 \pm 1.05$ & $33.3 \pm 1.04$ \\
\hline Mean \pm Std (birth weight (grams)) & $1107.8 \pm 223.4$ & $1156.1 \pm 192.1$ & $1129.9 \pm 210.6$ \\
\hline Mean \pm Std (crib score) & $6.8 \pm 3.4$ & $5.6 \pm 2.4$ & $6.3 \pm 3.1$ \\
\hline
\end{tabular}

\section{CRIB SCORE AND ITS RELATIONSHIP WITH MORTALITY AMONG THE STUDY GROUP}

Mean CRIB score among males was $6.8 \pm 3.4$ SD and mean CRIB score among females was $5.6 \pm 2.4$ SD. Total mean CRIB score among whole of the study population was $6.3 \pm 3.1 \mathrm{SD}$ (table I). 36.2\% $(n=92)$ newborns had CRIB score between $1-5,58.3 \%(n=148)$ had CRIB score between $6-10$ and 5.5\% $(n=14)$ had CRIB score between 11-15 (table II).

Overall mortality was found to be $54.7 \%$ $(n=139)$ male newborns during NICU stay
$45.3 \% \quad(n=115)$ female newborns were discharged (table III). Mean CRIB score was found to be $8.27 \pm 2.1$ SD among mortality group and it was 3.87 \pm 3.4 SD among newborns who were discharged. Independent t-test was applied to see the significance of difference among both groups. $P$-value was

found to be $0.000(<0.05)$ implying significant difference between two means with mean CRIB score was significantly higher in mortality group (table IV).

Percentage mortality was calculated among newborns with different CRIB score levels. Among newborns who had CRIB score between 
1-5 mortality was present in $4.3 \%(n=4)$ of neonates. Among newborns who had CRIB score between 6-10 mortality was present in $87.1 \%(n=121)$ of neonates and among newborns who had CRIB score between 11-15 mortality was present in $100 \%(n=14)$ of neonates. Chi-square-test was applied to see the significance of difference among the groups. $P$-value was found to be $0.000(<0.05)$ implying significant difference with significantly higher percentage mortality was noted among neonates with higher CRIB scores (table V).

Table-II: CRIB-score levels study in population.

\begin{tabular}{|c|c|c|}
\hline CRIB LEVELS & FREQUENCY & PERCENT \\
\hline $\mathbf{1 - 5}$ & 92 & 36.2 \\
\hline $\mathbf{6 - 1 0}$ & 148 & 58.3 \\
\hline $\mathbf{1 1 - 1 5}$ & 14 & 5.5 \\
\hline TOTAL & 254 & 100.0 \\
\hline
\end{tabular}

Table-III: Mortality in study population.

\begin{tabular}{|c|c|c|}
\hline GENDER & FREQUENCY & PERCENT \\
\hline MALES & 139 & 54.7 \\
\hline FEMALES & 115 & 45.3 \\
\hline TOTAL & 254 & 100.0 \\
\hline
\end{tabular}

Table-IV: Mean CRIB score among mortality and discharge group.

\begin{tabular}{|c|c|c|c|c|}
\hline MORTALITY & $\mathbf{N}$ & $\begin{array}{c}\text { CRIB SCORE } \\
\text { (MEAN) }\end{array}$ & $\begin{array}{c}\text { STD. } \\
\text { DEVIATION }\end{array}$ & $\begin{array}{c}\text { P-Value } \\
\text { (t-test) }\end{array}$ \\
\hline PRESENT & 139 & 8.27 & 2.1 & $<0.001$ \\
\hline ABSENT & 115 & 3.87 & 2.1 & $<$ \\
\hline
\end{tabular}

Table-V: Percentage mortality in different levels of CRIB score.

\begin{tabular}{|c|c|c|c|c|}
\hline CRIB SCORE & \multicolumn{2}{|c|}{ MORTALITY } & \multirow[t]{2}{*}{ Total } & P-value \\
\hline LEVELS & PRESENT & ABSENT & & \multirow{9}{*}{$<0.001$} \\
\hline \multirow{2}{*}{ 1-5 } & 4 & 88 & 92 & \\
\hline & $4.3 \% *$ & $95.7 \%$ & $36.22 \%$ & \\
\hline \multirow{2}{*}{$6-10$} & 121 & 27 & 148 & \\
\hline & $87.1 \%$ & $18.2 \%$ & $58.26 \%$ & \\
\hline \multirow{2}{*}{ 11-15 } & 14 & 0 & 14 & \\
\hline & $100 \%$ & $0 \%$ & $5.51 \%$ & \\
\hline \multirow{2}{*}{ TOTAL } & 139 & 115 & 254 & \\
\hline & $54.7 \%$ & $45.3 \%$ & $100 \%$ & \\
\hline
\end{tabular}

\section{DISCUSSION:}

The low birth weight babies are considered to be at high risk of mortality in early days of their life between 7 to 28 days. Now a days there is lot of technological improvement in assessing the weight of the babies before they are going to be delivered in the labor room by the gynecologist. The presence of intensive care neonatal units is a blessing for the children with low weight as they are being treated more professionally by the qualified pediatricians. There is lot of improvement in the prenatal care $^{[15]}$. Intensive care units have been specially designed to meet the needs of the neonatal care and are given the name of neonatal intensive care units which are available in the secondary and tertiary care 
hospitals ${ }^{[16]}$. Very low birth weight babies were considered to be at risk in their early life between 7-28 days particularly in the lower and middle income countries due to nonavailability of prenatal medicines, general facilities and the intensive care facilities ${ }^{[17]}$. World Health Organization and United Nations General Assembly have taken key steps to lower down the morbidity and the mortality in very low birth weight babies. They are providing guidelines to the member countries, UNAP, UNDP, UNICEF and WHO to take care of very low birth weight babies. Due to the reason, all the stakeholders were taken on board to reduce the morbidity and mortality of very low birth weight babies.

Rationale of this study was to gather data about the strength of CRIB score in predicting the outcome as if the outcome is predicted within first few hours after birth, the clinicians may intervene timely and with proper management serious morbidity and mortality rates may be reduced.

The new medications in the prenatal medicine have played a great role in reducing the neonatal mortality risks ${ }^{[19]}$. This is a small scale study which was carried out with limited resources. The validity and viability of CRIB and SNAPE scoring system may provide us better reliable results if the study is to be carried out at a larger scale. This study has provided us with information that early diagnosis of low weight babies can be made by using CRIB and SNAPE scoring which can reduce the mortality rate of the low weight birth babies.

The result of the study has also provided us with information that CRIB Scoring System can also be useful in all neonatal hospitals in letter and spirit with a little effort. It is therefore, recommended that more detailed study on this aspect should be carried out so that low birth weight babies can be diagnosed at the earlier stage for better treatment.

Further large-scale trials are needed to validate its role in clinical settings. With improvements in technology, understanding of neonatal physiology and improvement in risk prediction score systems it is possible to predict the high risk neonates at an earlier time and to reduce the morbidity and mortality among them. We recommend its routine use in clinical settings. We also intend to compare CRIB and SNAPE scoring systems in future studies at our setup.

\section{CONCLUSION:}

Mean CRIB score was significantly higher in mortality group and significantly higher percentage mortality was noted among neonates with higher CRIB scores.

\section{CONFLICT OF INTEREST:}

There is no declared conflict of interest.

\section{ETHICAL REVIEW COMMITTEE:}

Ethical review committee of the said institute has reviewed and approved this article.

\section{REFERENCES:}

1. World Health Organization. Neonatal and Prenatal Mortality: Country, Regional and Global Estimates [Internet]. Geneva, Switzerland: World Health Organization; 2006.

2. Lawn JE, Cousens S, Zupan J. Lancet Neonatal Survival Steering Team. 4 million neonatal deaths: when? where? why? Lancet. 2005;365:891-900.

3. Carlo A, Goudar SS, Jehan I, Chomba E, Tshefu A, Garces A, et al. High Mortality Rates for Very Low Birth Weight Infants in Developing countries despite training. Pediatrics. 2010;126;e1072.

4. Sarquis ALF, Miyaki M, Cat MNL. CRIB score for predicting neonatal mortality risk. J Pediatr. 2002;78:225-9.

5. Baumer $\mathrm{JH}$, Wright $\mathrm{D}$, Mill T. Illness severity measured by CRIB score: a product of changes in perinatal care. Arch Dis Child. 1997;77:211-5.

6. Cockburn F, Cooke R, Gamsu H. International Neonatal Network. The CRIB (Clinical risk index for babies) score a tool for assessing initial neonatal risk and comparing performance of neonatalintensive care units. Lancet. 1993;342:193-8.

7. De Brito ASJ, Matsuo T, Gonzalez MRC, Carvalho ABR, Ferrari LSL. CRIB score, 
birth weight and gestational age in neonatal mortality risk evaluation. Rev SaudePublica. 2003;37:597-602.

8. Vohr BR, Wright LL, Dusick AM. Center differences and outcomes of extremely low birth weight infants. Pediatrics. 2004; 113:781-9.

9. Lezzon L. Risk adjustment for measuring health care outcomes 3rd ed. Chicago: IL Health Administration Press; 2003.

10. Boutaleb Y. Maternal mortality and perinatal mortality. Journal de Gynécologie, Obstétriqueet Biologie de la Reproduction. 1982;2:99-102.

11. Bouvier-Colle M-H. Maternal morbidity in West Africa. Results of a population survey in Abidjan, Bamako, Niamey, Nouakchott, Ougadougou, Saint-Louis, Kaolack. France: Ministère des Affaires étrangères Coopérationet Francophonie; 1998.

12. Bugalho A, Bergström S. Value of prenatal audit in obstetric care in the developing world: a ten year experience of the Maputo model. Gynecologic and Obstetric Investigation. 1993;36:239-43.

13. Blencowe $\mathrm{H}$, Cousens $\mathrm{S}$, Oestergaard MZ. National, regional, and worldwide estimates of preterm birth rates in the year 2010 with time trends since 1990 for selected countries: a systematic analysis and implications. Lancet. 2012;379:21624.

14. Hübner ME, Ramírez R. Survival, viability and prognosis of premature infant. Rev Med Chil. 2002;130:931-8.

15. MCN Am J Matern Child Nurs. 2016; Improving Prenatal Care Minority Women, PMC, May-June 41 (3) 147-153

16. Fileen T Lake, Sunny G Hallowell, Higher Quality of Care and Patient Safety
Associated with Better NICU Work Environment, Journal of Nursing Care Quality 2016, Jan-Mar 31(1) Page 24-32.

17. Indira Narayanan, Jesca Nsungwa-Sabiti, Journal of Maternal Health Neonatology and Perinatology, 2019 5(10) Page 29-35.

18. Dr. Mekalai Suresh Kumar, Morbidity and mortality pattern of very low birth weight infants admitted in SNCU in a South Asian tertiary care centre, International Journal of Contemporary Peadiatrics, 2018, May 5 (3), Page 720-725.

19. Vakrilova L, Stancheva B, Dimitrov A, Nikolov $A$. The very low birth weight and very low gestational age neonates survival, prognosis and perspectives. Akush Ginekol (Sofiia). 2011;50:31-6.

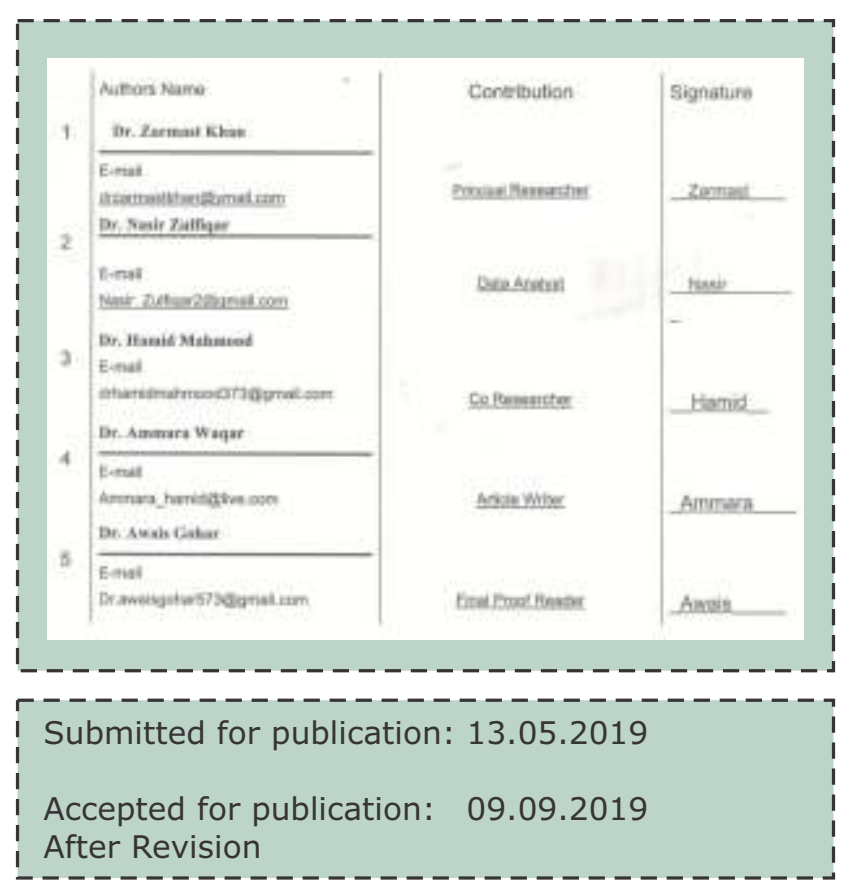

